\title{
NAVEGAR É PRECISO: O MAR NA POESIA INFANTIL E JUVENIL
}

\author{
Karina de Oliveira ${ }^{1}$
}

"Navegar é preciso, viver não é preciso"1 (...). É de longa data que o mar é rememorado na literatura, exemplo disto é a célebre frase utilizada por um general romano, que tempos depois se imortalizou em um poema de Fernando Pessoa. Essa frase era dita aos marinheiros que sentiam medo recusando-se a navegar durante a guerra. Detendo-nos à primeira parte do verso, navegar é uma tarefa muito parecida com a de ler, já que ambas exploram um espaço que, a princípio, é desconhecido, mas, na maioria das vezes, revela-nos fabulosas histórias e experiências e aventuras únicas. Assim como um general instiga seus marinheiros, igualmente os leitores necessitam dos mediadores estimulando-os em suas leituras. No primeiro caso, o intuito é formar grandes navegadores e exploradores, do mesmo modo, no segundo caso, os mediadores precisam formar leitores capazes de explorar os mais distintos livros. Assim, a obra apresentada neste texto, além de se ocupar com a promoção da leitura, apresenta uma grande contribuição a todos os que se dedicam à formação de leitores.

Maré de livros é um instigante volume realizado pelo grupo de investigação LITER2 $1^{2}$ que está inscrito na Universidade de Santiago de Compostela (USC) pela Rede Temática “As Literaturas Infantis e Juvenis do Marco Ibérico e Iberoamericano” (LIJMI). Trata-se de uma coletânea de ensaios que nos permite um aprofundamento no estudo da poesia infantil e juvenil, cujos artigos organizam-se em torno de uma mesma unidade - o mar na poesia infantil e juvenil - tomada em suas diversas faces.

Sua diversidade dá-se tanto por meio dos textos, quanto pelos seus autores, já que estes são pesquisadores, editores, escritores e ilustradores, todos dedicados ao trabalho com a Literatura Infantil e Juvenil. Justamente por isto, a obra é importante para promover a leitura e formar mediadores de leitura, destinando-se a educadores, bibliotecários, pais ou responsáveis por crianças e/ou adolescentes.

Michèle Petit (2008, p.166) ${ }^{3}$ recorda-nos que os mediadores necessitam não apenas iniciar as crianças e os jovens na leitura, mas também acompanhá-los durante todo o trajeto, podendo passar por várias turbulências e interrupções. Assim, também é função do mediador

\footnotetext{
${ }^{1}$ Doutoranda da Universidade de Santiago de Compostela - USC (Galícia-Espanha).

Professora do Departamento de Letras da UNIFEV - Centro Universitário de Votuporanga-SP. E-mail Ka_letrasunesp@yahoo.com.br
} 
auxiliar os leitores iniciantes a ultrapassar os mares agitados ou "umbrais", como prefere Petit.

No que se refere à organização, o livro é dividido em seis partes: Apresentação, Estudos, Encontros com autores, Encontros com editores, Ateliers e Exposições. Na apresentação, José António Gomes revela que o mar é um livro de mil histórias e poemas citando alguns títulos, como, por exemplo, Odisseia e Os Lusíadas que representam o mar como motivo, tema e espaço simbólico. Nesse passo, a literatura para crianças e jovens também mostra gosto pelas águas e é a poesia o gênero privilegiado nesta obra. Muitas vezes, este público tarda a conhecer o mar, por isso as indicações de obras presentes em Maré de livros pode permitir esse encontro, ainda que de forma simbólica.

Como este trabalho é resultado de mais uma reunião de pesquisadores do $15^{\circ}$ Encontro Luso-Galaico-Francês do Livro Infantil, realizado na Biblioteca Almeida Garrett do Porto, em Novembro de 2009, há pessoas de três geografias culturais, linguísticas e territoriais: Galícia, Portugal e França. Estas culturas apresentam não só a relação com o Atlântico, mas partilham também o trabalho com a leitura e com a literatura infantil e juvenil.

No bloco intitulado Estudos, são agrupados três ensaios. O primeiro deles, em águas portuguesas, José António Gomes, Ana Margarida Ramos e Sara Reis da Silva fazem um rastreamento de escritores que apresentam uma produção literária importante direcionada aos pequenos e aos jovens leitores.

Em forma de recorte, os pesquisadores comentam as obras de Castrim (1920-2002), Matilde Rosa Araújo (1921-), Couto Viana (1923-), Luísa Ducla Soares (1939-), António Torrado (1939-), Pina (1943-), Letria (1951-), Álvaro Magalhães (1951), e ainda outros escritores. Castrim (1920-2002) leva o leitor além das aparências mais óbvias; Matilde Araújo (1921-), por sua vez, é uma das vozes mais singulares da poesia portuguesa para a infância; e Couto Viana (1923-), por seu turno, enriquece a tradição dos bestiários poéticos, destacandose no domínio da ecopoesia.

Importa mencionar também os nomes de Vergílio Alberto Vieira (1950-), cuja vertente é caracterizada pelo lúdico e pelas críticas sociais; José Fanha (1951-), por sua vez, recria algumas rimas de maior divulgação, tais como trava-línguas e lengalengas, e a produção de António Mota (1957-) é marcada pela utilização de um discurso próximo do coloquial. Enquanto Jorge Sousa Braga (1957-) revela originalidade em seus textos poéticos, João Pedro Mésseder (1957-), por meio dos seus, suscita reflexões a partir de um olhar minucioso 
direcionado ao universo infantil, manifestando uma voz interior que reflete sobre o mundo e os homens. Já a produção de Alexandre Honrado (1960-) prioriza os elementos da natureza por meio da personificação; a de Nuno Higino (1960-), por seu turno, destaca-se pela forma intensamente lírica e o modo como combina uma atenta observação da realidade com a simplicidade de um registro. E, enfim, a produção de João Manuel Ribeiro (1968-) é relevante por explorar, principalmente, o lúdico e o universo dos animais.

Especialmente sobre a poesia para a infância e o mar, vale ressaltar que este é um elemento de grande relevância na identidade portuguesa. Escritores que se sobressaem a partir dessa temática são: Sophia de Mello Breyer Andresen (1919-2004), com o conto A Menina do Mar (1958); O Romance das Ilhas Encantadas (1964), de Jaime Cortesão (1884-1960); O Mar na Cultura Popular Portuguesa (1998), de Maria Isabel de Mendonça Soares (1922-). Tais textos são alguns dos pioneiros no domínio específico da literatura infantil portuguesa e remontam o mar como mote poético.

Algumas outras obras publicadas entre 2000 e 2008 são: A moeda do Sol (2006), de Mário Castrim; A casa do silêncio (2000), coletânea de poetas portugueses, mas com olhar especial para o poema Búzio do mar, de Luísa Ducla Soares. E da mesma autora a coletânea Planeta Azul (2008), cujo mar é retomado de diversas formas; O limpa-palavras e outros poemas (2000), de Álvaro Magalhães; Jogos, Versos e Redacções (2001), de Teresa Rita Lopes; Como quem diz (2005), de António Torrado; Breviário (2004), de João Pedro Méssseder e Francisco Duarte Mangas, para mencionar apenas alguns títulos. Sobre tais obras, há uma série de recursos e elementos essenciais que fazem destes textos grandes produções, como a valorização da dimensão nonsensical (do absurdo ao insólito), a metalinguagem, as vozes infantis e adultas, a influência popular e tradicional revisitadas, a reinvenção verbal e o jogo sonoro.

Já em águas galegas, antes de analisar a presença do mar na poesia infantil do século XXI, as autoras Blanca-Ana Roig Rechou, Marta Neira Rodríguez e Eulalia Agrelo Costas mencionam que há ainda pouca atenção para esse gênero. Mesmo que sua produção seja menor que a da narrativa, sua face está mais vista nas produções literárias dos últimos dez anos. É importante ressaltar que neste livro o elemento mar é visto em culturas distintas, logo as abordagens em cada produção apresentam-se de formas únicas. No entanto, ao longo da civilização, o mar também carrega consigo traços comuns em diferentes culturas. 
Geograficamente falando, a Galícia está formada por uma imensidão de água do mar e, sendo assim, é algo presente tanto na identidade individual quanto na coletiva.

No que confere à poesia, as autoras abordam a classificação realizada por Roig (2000), fazendo distinção entre poesia é jogo, poesia é música, poesia é conto e poesia é magia. As duas primeiras vertentes revelam um conjunto de composição que proporciona o contato inicial da infância com a poesia lírica. Essas vertentes possuem estruturas bem repetitivas, simples no ritmo, na rima, no léxico e, ainda, na musicalidade. Algumas delas são cantigas, adivinhações, parlendas etc. A presença do mar é especialmente vista em tais obras. Representantes destas vertentes são: Xoán Babarro (1947), Antón Cortizas (1945), Gloria Sánchez (1958).

Na corrente poesia é conto estão inseridos relatos, fábulas e contos transmitidos, inicialmente, de forma oral, em prosa ou em verso, retratando feitos históricos e vidas de santos por meio de elementos fantásticos, maravilhosos, humorísticos e lúdicos. Alguns autores se repetem, porém outros se somam a eles, tais como: Xoán Babarro (1947), Ramón Caride (1957), Antonio García Teijeiro (1952), Xosé Miranda (1955) e Gloria Sánchez (1958).

A última, por seu turno, poesia é magia, enriquece toda produção, pois apresenta produções poéticas mais livres, experimentais e com figuras retóricas um pouco mais complexas pelos recursos estéticos. Entre os escritores dessa corrente, merecem atenção especial: Xoán Babarro (1947), Ana María Fernández (1949), Antón Cortizas (1945), Helena Vilar Janeiro (1940).

Para encerrar esta parte, Maria Madalena Marcos Carlos Teixeira da Silva tece reflexões sobre o subsistema literário juvenil, revelando que, geralmente, as obras destinadas a crianças e a jovens estão inseridas em um mesmo contexto ou estatuto. Sob o ponto de vista da pesquisadora, é necessário delinear a distinção entre literatura juvenil e infantil de acordo com aquilo que os mediadores do sistema literário pensam que seja adequado aos diferentes destinatários. Essa distinção basicamente traduz-se numa diferenciação de formas e gêneros literários e, posteriormente, na escolha de temas e motivos. Assim, a literatura juvenil deve ser constituída como objeto de estudo autônomo em relação à literatura infantil.

Em Encontro com escritores, três autores confidenciam-nos suas experiências com o mar. Marcos Calveiro revela-nos que, desde criança, se sente maravilhado com a bravura e a beleza do mar. Seu primeiro mar foi aquele visto através das páginas de livros da biblioteca de 
seus pais, fazendo suas fascinantes viagens por meio de atlas, assim como por meio da literatura. Calveiro viveu também inúmeras aventuras que são relembradas em suas obras, como em seu último livro O canto dos peixes (2008).

Já a escritora Luísa Ducla Soares comenta que nasceu praticamente com um "pé na terra e o outro dentro d’água”. Na infância, a autora vivia ao redor da Torre de Belém e da Escola de Pescadores, em Portugal, sendo assim, teve muito contato com o mar. E por meio dos elementos marítimos, sua imaginação flui livremente na escrita de seus textos.

Nuno Higino, por sua vez, buscou durante muito tempo uma palavra apropriada para falar sobre o mar de sua infância. Sendo assim, encontrou a palavra encoradoiro que significa represa de águas. Quando as águas de sua infância encontravam uma barreira que as impedia de seguir, elas encoravam, ou seja, juntavam-se. O escritor afirma que não se lembra de quando conheceu o mar, prefere, pois, alimentar as ideias de sua imaginação.

Sob o título de Encontro com editores, Belén López Vázquez, da Baía Edicións apresenta-nos alguns dados: dos 120 títulos destinados ao público infantil e juvenil, apenas 16 utilizam a temática marinha. Retornando ao século XII, por exemplo, Paio Gomez Chariño de Soutomaior introduziu a temática do mar nas suas cantigas de amor, Martin Codax, Xoán Zorro, Rosalía de Castro (1859) também o fizeram.

A autora salienta que embora o mar esteja presente em algumas obras de importância universal, ele não apresenta o devido reconhecimento na literatura galega. Por fim, comenta que não há uma tradição histórica que remonte ao mar na literatura infantil galega.

Ateliers é um bloco organizado por Alexia Dotras Bravo, Mar Fernández Vázquez, Carmen Ferreira Boo e Esther de León Viloria. As autoras dividiram seu texto - destinado a mediadores - em quatro partes: Estudos teóricos; Materiais didáticos; Antologias selecionadas e Enlaces na web. Na primeira parte, de cunho mais teórico, a obra mencionada é A poesia infantil no século XX (2000-2008), coordenada por Blanca-Ana Roig, Isabel Soto e Marta Neira.

Na segunda parte, com nuances mais pedagógicas, são apresentadas as obras Disfrutar escribindo. A narración e a poesia nas aulas (1990) e A poesia necesaria. Lectura e creación poética na aula (2009), de Antonio García Teijeiro e o livro Verso a Verso. A poesía sae das aulas (1997), de Consuelo Varela Fernández.

Já na terceira explanação, sobre as Antologías selecionadas, outro livro de Teijeiro é comentado: Os novos versos (1998). O libro dos cen poemas. Antoloxía da poesia infantil 
galega (2002), de Xosé Maria Alvarez Cáccamo e Marisa Nuñez e Poetízate (2006), de Fran Alongo. Entre os materiais virtuais, as autoras salientam uma série de sítios da web de colégios de Educação Infantil e Primária, centros escolares bem como de escritores. E, finalmente, são mostradas propostas de atividades práticas, lúdicas e criativas para serem realizadas durante as aulas.

Exposições, tópico que encerra a obra, é revisitado pelo ilustrador Xosé Covas que nos conta um pouco sobre a exposição Vai de Mar. O trabalho teve a participação de 17 ilustradores (previamente selecionados) e alguns destes nomes são: Suso Cubeiro, Irene Fra, Noemí López, Pepe Carreiro, Lázarro Enríquez, Kiko Silva, Federico Fernández. A partir dos recursos escolhidos pelos artistas, eles expressam seus sentimentos, posicionamento social e filosófico, dentre tantos outros elementos. A exposição foi inaugurada em Valência, no ano de 2005, seguiu até a Bretanha francesa, Santiago de Compostela e chegou, enfim, ao Porto.

Ao fim desta navegação, observamos que este livro teve o intuito de adentrar no mundo da poesia infantil e juvenil, destacando a magia do mar por meio de significativas obras portuguesas e galegas, de conversas com editores, escritores e pesquisadores, mostrando a atuação destas indispensáveis personagens para a formação do pequeno e do jovem leitor. E, finalmente, buscando mais um verso de Pessoa: [...] “o que é necessário é criar”, criar caminhos apropriados de leitura a estes leitores, para que possam, ao longo de suas jornadas, navegarem sozinhos por diversos mares

\section{Referência}

GOMES, José Antonio et al. (orgs.). Maré de livros. Porto: Deriva Editores, 2010. 116 p.

\footnotetext{
${ }^{1}$ Disponível em: <http://www.jornaldepoesia.jor.br/fpesso05.html>. Acesso em: 24 abr. 2012.

${ }^{2}$ Literatura galega. Literatura Infantil e Xuvenil. Investigacións literarias, artísticas, interculturais e educativas. Lecturas textuais e visuais” é um grupo interdisciplinar, com especialistas de Filologia, Belas Artes, Didáctica da Língua e Literatura e Didáctica da Expressão Plástica, que está inscrito na Universidade de Santiago de Compostela (GI-1839), na Euro- -região Galiza-Norte de Portugal, promovida pelo Centro de Estudos Euroregionais Galiza-Norte de Portugal, uma entidade sem fins lucrativos e formada por universidades galegas e portuguesas, e no Catálogo de Grupos de Investigação da Junta da Galiza (09IDI0006). É possível consultar toda a informação sobre os seus membros e linhas de investigação em: http://imais.usc.es/grupofi cha.asp?idpersoatipogrupo=88297\& $\mathrm{i}=\mathrm{gl} \& \mathrm{~s}=-2-26-148-150 \& \mathrm{v}=\#$ membros .

${ }^{3}$ PETIT, Michèle. Os jovens e a leitura: uma nova perspectiva. Trad. Celina Olga de Souza. São Paulo: Ed.34, 2008.
} 